Supplement of Solid Earth, 10, 2103-2113, 2019

https://doi.org/10.5194/se-10-2103-2019-supplement

(C) Author(s) 2019. This work is distributed under

the Creative Commons Attribution 4.0 License.

(c) (1)

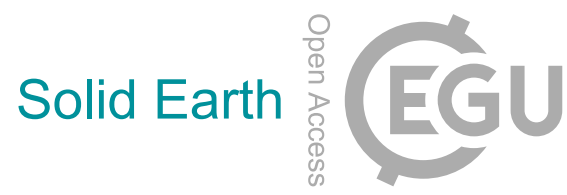

Supplement of

\title{
The effect of effective rock viscosity on 2-D magmatic porosity waves
}

Janik Dohmen et al.

Correspondence to: Janik Dohmen (dohmen@geophysik.uni-frankfurt.de)

The copyright of individual parts of the supplement might differ from the CC BY 4.0 License. 


\section{Supplementary Material}
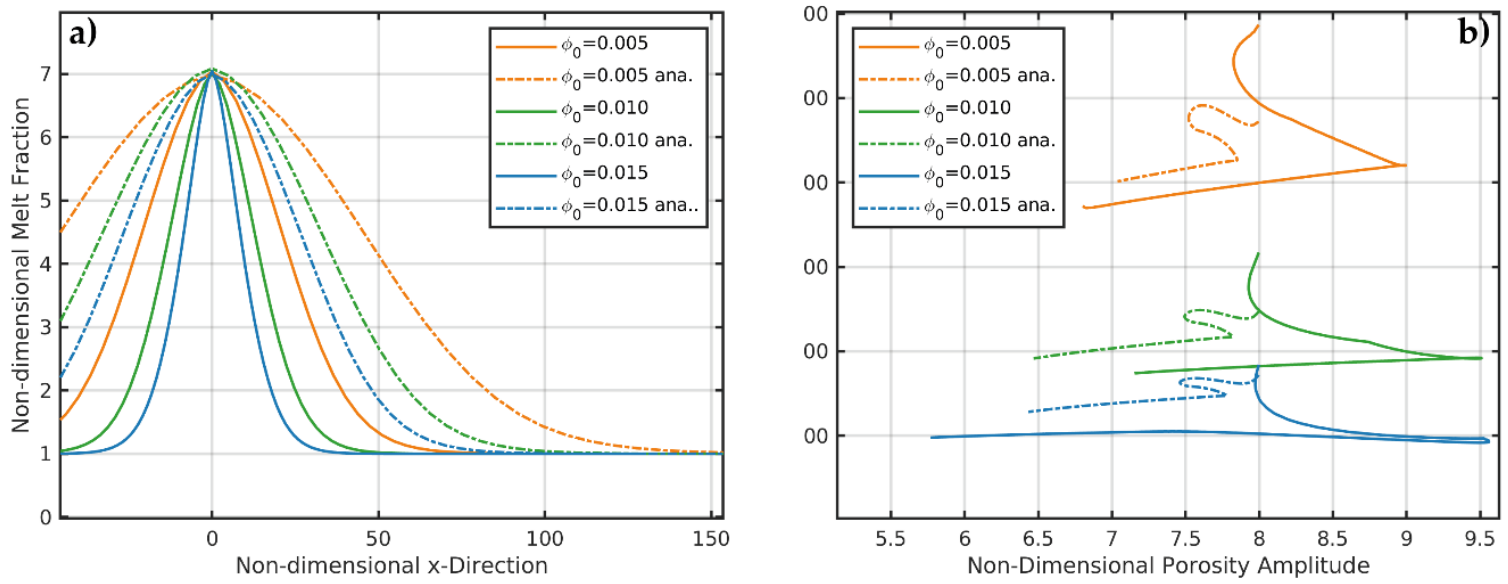

Fig. 1: Like Fig. 8 but with the scaling used by Richard et al. (2012). 